\title{
PERKIRAAN SEDIMENTASI PADA TAHUN 2018 DI WADUK JATILUHUR, KABUPATEN PURW AKARTA
}

\section{Sedimentation Prediction in Jatiluhur DAM, Purwakarta District}

\section{Ulfah Sarach Sheftiana1)* Muhammad Yanuar Jarwadi Purwanto ${ }^{2)}$ dan Suria Darma Tarigan ${ }^{3}$}

\author{
${ }^{1}$ Pengelolaan Sumberdaya Alam dan Lingkungan, Sekolah Pascasarjana, IPB University, Kampus IPB \\ Baranangsiang Bogor \\ ${ }^{2}$ Departemen Teknik Sipil dan Lingkungan, Fakultas Teknologi Pertanian, IPB University, Jl. Meranti \\ Kampus IPB Dramaga Bogor \\ ${ }^{3}$ Departemen Ilmu Tanah dan Sumberdaya Lahan, Fakultas Pertanian, IPB University, Jl. Meranti Kampus \\ IPB Dramaga Bogor
}

\begin{abstract}
Jatiluhur DAM is one of the multipurpose DAMs in West Java with the design of hydroelectric power plants, water supply in industry, irrigation, fisheries, tourism and flood control. Based on the final report of Juanda Public Corporation in 2000 that the DAM volume in 1964 was 2,970 million $\mathrm{m}^{3}$, in 1987 it was 2,556 million $\mathrm{m}^{3}, 1995$ was 2,456 million $\mathrm{m}^{3}$ and in 2000 was 2,448 million $\mathrm{m}^{3}$. This shows that the DAM volume has decreased by 522 million $\mathrm{m}^{3}$ over a period of 36 years at an altitude of \pm 107 masl. The purpose of this study are to calculate sedimentation in the Jatiluhur DAM in 2018. TSS measurements using SNI 06-6989.3-2004 and calculation of sedimentation using direct measurement methods. The results showed that the total sediment in DAM inlet is 859,368.40 tons year ${ }^{-1}$ and the reservoir outlet is 92,553.33 tons year ${ }^{-1}$. Based on this data, the total sediment deposited in the Jatiluhur Reservoir in 2018 was $766,815.07$ tonnes. So it needs handling in reducing sediment so that the reservoir does not experience silting.
\end{abstract}

Keywords: DAM, Jatiluhur, sedimentation

\section{ABSTRAK}

Waduk Jatiluhur merupakan salah satu waduk serbaguna di Jawa Barat dengan peruntukkan Pembangkit Listrik Tenaga Air (PLTA), penyediaan bahan baku air minum (PDAM) dan industri, penyediaan air irigasi, perikanan, pariwisata dan pengendalian banjir. Berdasarkan laporan akhir Perum Juanda pada tahun 2000 bahwa volume waduk pada tahun 1964 adalah 2,970 juta $\mathrm{m}^{3}$, pada tahun 1987 adalah 2,556 juta $\mathrm{m}^{3}$, tahun 1995 adalah 2,456 juta $\mathrm{m}^{3}$ dan pada tahun 2000 adalah 2,448 juta $\mathrm{m}^{3}$. Hal ini menunjukkan bahwa volume waduk telah berkurang sebanyak 522 juta $\mathrm{m}^{3}$ dalam kurun waktu 36 tahun pada ketinggian \pm 107 mdpl. Tujuan penelitian ini adalah untuk menghitung sedimentasi di Waduk Jatiluhur pada tahun 2018. Pengukuran TSS menggunakan SNI 06-6989.3-2004 dan perhitungan sedimentasi menggunakan metode pengukuran langsung. Hasil penelitian menunjukkan bahwa total sedimen di inlet waduk adalah 859,368.40 ton tahun ${ }^{-1}$ dan outlet waduk adalah $92,553.33$ ton tahun ${ }^{-1}$. Berdasarkan data tersebut maka total sedimen yang mengendap di Waduk Jatiluhur pada tahun 2018 adalah 766,815.07 ton. Sehingga diperlukan penanganan dalam mengurangi sedimen agar waduk tidak mengalami pendangkalan.

Kata kunci: Waduk, Jatiluhur, sedimentasi

\section{PENDAHULUAN}

Berdasarkan laporan akhir Perum Juanda pada tahun 2000 bahwa volume waduk pada tahun 1964 adalah 2,970 juta $\mathrm{m}^{3}$, pada tahun 1987 adalah 2,556 juta $\mathrm{m}^{3}$, tahun 1995 adalah 2,456 juta $\mathrm{m}^{3}$ dan pada tahun 2000 adalah 2,448 juta $\mathrm{m}^{3}$. Hal ini menunjukkan bahwa volume waduk telah berkurang sebanyak 522 juta $\mathrm{m}^{3}$ dalam kurun waktu 36 tahun pada ketinggian $\pm 107 \mathrm{mdpl}$. Analisis sedimentasi atau bahan terangkut akibat erosi diperlukan untuk mengetahui berapa jumlah bahan yang diendapkan di bagian hilir serta kerusakan yang dapat ditimbulkan bila bahan terangkut tersebut melewati pintu - pintu saluran irigasi.

Menurut Tjakrawarsa et al. (2014) bahwa sedimentasi merupakan proses pengendapan partikelpartikel tanah hasil erosi yang tersuspensi didalam air dan diangkut oleh aliran air dimana kecepatan aliran telah menurun. Sedimentasi yang terjadi pada waduk dipengaruhi oleh fisiografi dan hidroklimatologi daerah tangkapan, aktivitas dan perilaku pemanfaatan lahan di daerah tangkapan serta pola operasi waduk (Moerwanto dan Putuhena, 2010).

Faktor yang mempengaruhi erosi adalah karakteristik hujan, kemiringan lereng, tutupan lahan dan kemampuan tanah untuk menyerap dan melepas air ke dalam lapisan tanah dangkal, dampak dari erosi tanah dapat menyebabkan sedimentasi di sungai sehingga dapat mengurangi daya tampung sungai (Suripin, 2002). Gangguan terhadap fungsi Waduk Jatiluhur dapat menimbulkan kerugian yang besar seperti terganggunya sistem irigasi, terganggunya pasokan air baku untuk warga sekitar maupun industri, rusaknya turbin Pembangkit Listrik Tenaga Air (PLTA); tingginya biaya pemeliharaan, 
sejumlah pintu air bendungan tidak dapat dioperasikan otomatis dan turunnya umur ekonomis peralatan (life cycle) akibat korosi, rusaknya budidaya perikanan dan terganggunya kegiatan pariwisata (Hamzah et al., 2016). Oleh karena itu perlu dilakukan perhitungan sedimentasi sebagai dasar bentuk pengelolaan sedimentasi di Waduk Jatiluhur.

Penelitian ini bertujuan untuk menghitung prediksi bes arnya total sedimen di Waduk Jatiluhur pada tahun 2018. Informasi yang dihasilkan diharapkan dapat menjadi pertimbangan bagi pembuatan strategi kegiatan rehabilitasi di DAS dan Waduk Jatiluhur.

\section{BAHAN DAN METODE}

Penelitian dilakukan di Waduk Jatiluhur, Kabupaten Purwakarta, Jawa Barat. Titik pengambilan sampel air Waduk Jatiluhur dilakukan di inlet dan outlet Waduk Jatiluhur. Parameter yang diukur untuk dapat menghitung sedimentasi adalah parameter TSS. Pengambilan sampel dilakukan setiap bulan pada tahun 2018.

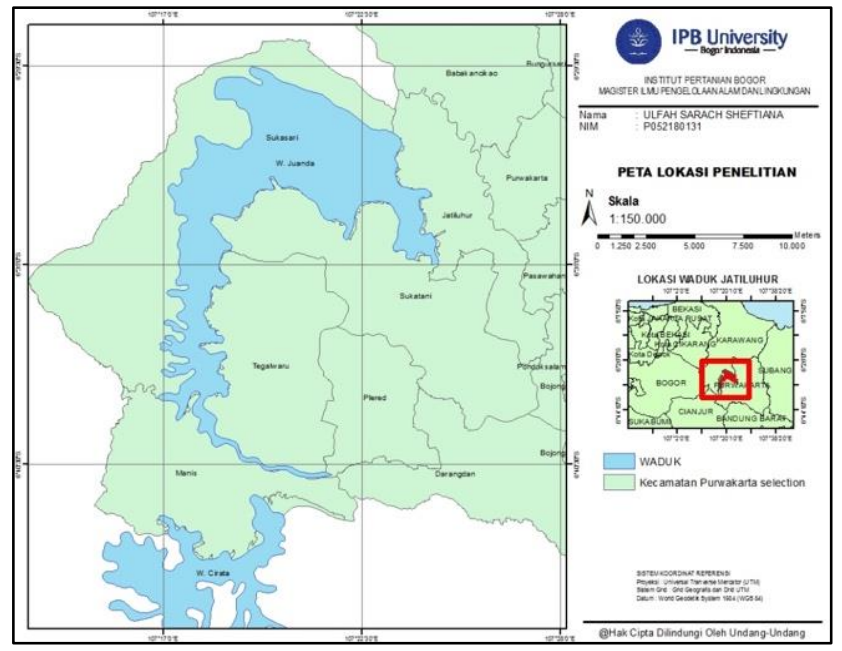

Gambar 1. Peta lokasi penelitian

Bahan dan alat yang dibutuhkan untuk mengukur kadar TSS adalah water grab sampler, botol sampel, water quality checker, dan perahu.

Debit inlet dan outlet Waduk Jatiluhur diambil setiap hari selama satu tahun penuh oleh Perum Jasa Tirta II. Data debit yang digunakan adalah data pada tahun 2018. Pengambilan sampel air untuk menghitung sedimen berdasarkan SNI 6989.57: 2008 yaitu danau atau waduk yang kedalamannya lebih dari $100 \mathrm{~m}$, titik pengambilan contoh ditambah sesuai keperluan kemudian dicampurkan. Dalam hal ini air yang diambil adalah pada kedalaman $0 \mathrm{~m}$, $2 \mathrm{~m}, 4 \mathrm{~m}$ dan $8 \mathrm{~m}$ dengan volume air yang diambil di setiap kedalaman adalah $1 \mathrm{~L}$. Sampel air tersebut dianalisis kadar sedimen di laboratorium. Analisis sedimen dilakukan dengan penyaringan sampel air mengacu pada SNI 066989.3-2004 Badan Standar Nasional tentang cara uji total padatan tersuspensi secara gravimetri. Formula perhitungan kadar sedimen yaitu :

$$
C=\frac{(b-a)}{\text { volume air }} \mathrm{mg} / \mathrm{l}
$$

$$
\begin{aligned}
& \text { dimana: } \\
& \mathrm{C}=\text { konsentrasi kadar sedimen } \\
& \mathrm{a}=\text { berat awal kertas saring } \\
& \mathrm{b}=\text { berat akhir kertas saring (setelah penyaringan) }
\end{aligned}
$$

Debit sedimen (Qs) sedimen dalam aliran air dinyatakan dalam besaran laju sedimentasi (dalam satuan $\mathrm{kg} \mathrm{\operatorname {det } ^ { - 1 } \text { , ton hari }}{ }^{-1}$ atau ton tahun ${ }^{-1}$ ). Debit sedimen (Qs) dihitung dengan pengukuran langsung menggunakan persamaan (Tjakrawarsa et al., 2014) :

$$
Q s=k x C \times Q
$$

dimana:

$$
\begin{array}{ll}
\text { Qs } & \left.=\text { debit sedimen (ton hari }{ }^{-1}\right) \\
\mathrm{k} & =0.0864 \\
\mathrm{C} & =\text { konsentrasisedimen }\left(\mathrm{mg} \mathrm{l}^{-1}\right) \\
\mathrm{Q} & =\text { debit air }\left(\mathrm{m}^{3} \text { detik }^{-1}\right)
\end{array}
$$

Kurva lengkung debit sedimen merupakan grafik yang menampilkan hubungkan antara debit sedimen (Qs) dengan debit alirannya (Q) dengan sumbu $\mathrm{x}$ adalah $\mathrm{Q}$ dan sumbu Y adalah Qs dengan persamaan: $Q s=a Q^{b}$. Kurva tersebut nantinya akan digunakan untuk menghitung besaran sedimentasi berdasarkan data debit rata-rata harian selama satu tahun.

\section{HASIL DAN PEMBAHASAN}

\section{Konsentrasi Sedimen}

Sedimen terdiri dari semua partikel detrital, anorganik, atau organik yang akhirnya mengendap di dasar air tubuh (Burton, 2018). Pengukuran TSS dilakukan setiap bulan dengan kedalaman $0 \mathrm{~m}, 2 \mathrm{~m}$, dan $4 \mathrm{~m}$. Titik sampling dilakukan di inlet Waduk Jatiluhur yang berada pada daerah Parung Kalong. Hasil pengukuran TSS (konsentrasi sedimen) dan debit di inlet Waduk Jatiluhur disajikan pada Tabel 1 .

Tabel 1. Hasil pengukuran inlet

\begin{tabular}{cccc}
\hline $\begin{array}{c}\text { Tanggal } \\
\text { Pengukuran }\end{array}$ & $\begin{array}{c}\text { C (Konsentrasi } \\
\text { Sedimen }) \\
\left(\mathrm{mg} \mathrm{l}^{-1}\right)\end{array}$ & $\begin{array}{c}\text { Q } \\
(\text { debit }) \\
\left(\mathrm{m}^{3} \mathrm{det}^{-1}\right)\end{array}$ & $\begin{array}{c}\text { QS (Debit } \\
\text { Sedimen }) \\
\left(\mathrm{kg} \mathrm{det}^{-1}\right)\end{array}$ \\
\hline $16 / 01 / 18$ & 260 & 76.03 & 19.77 \\
$13 / 02 / 18$ & 160 & 184.76 & 29.56 \\
$18 / 03 / 18$ & 147.5 & 114.45 & 16.88 \\
$17 / 04 / 18$ & 230 & 121.94 & 28.05 \\
$15 / 05 / 18$ & 95 & 75.57 & 7.18 \\
$26 / 06 / 18$ & 50 & 242.32 & 12.12 \\
$17 / 07 / 18$ & 145 & 149.35 & 21.66 \\
$14 / 08 / 18$ & 180 & 148.20 & 26.68 \\
$13 / 09 / 18$ & 170 & 70.69 & 12.02 \\
$15 / 10 / 18$ & 182.5 & 51.44 & 9.39 \\
$13 / 11 / 18$ & 242.5 & 351.61 & 85.27 \\
$13 / 12 / 18$ & 192.5 & 305.12 & 58.74 \\
\hline
\end{tabular}

Berdasarkan data hasil pengukuran debit inlet Waduk Jatiluhur dan konsentrasi (Cs), maka dapat dihitung debit sedimen. Setelah mendapatkan nilai debit sedimen maka membuat persamaan lengkung debit sedimen, yaitu grafik hubungan antara Q dan Qs (Gambar 2). 


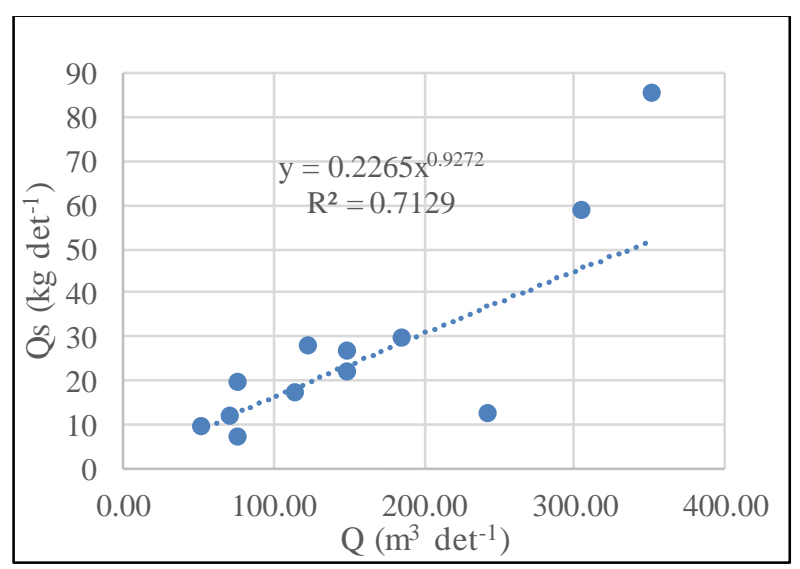

Gambar 2. Kurva lengkung debit sedimen inlet Waduk Jatiluhur

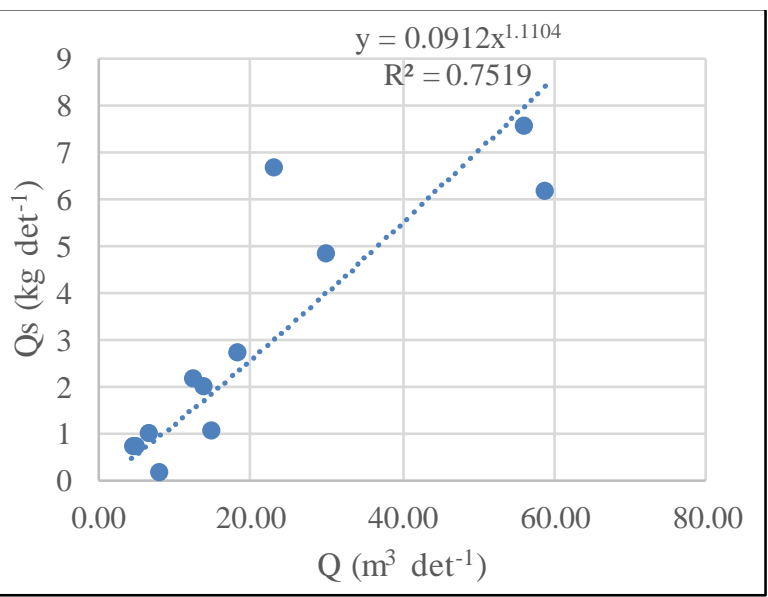

Gambar 3. Kurva lengkung debit sedimen outlet Waduk Jatiluhur

Setelah mendapatkan debit harian selama satu tahun dan dikonversi ke dalam persamaan lengkung debit sedimentasi, maka menentukan debit sedimen (Qs) dalam ton hari $^{-1}$. Debit sedimen (Qs) dalam ton/hari dihitung kembali menjadi satuan ton $\mathrm{ha}^{-1}$ tahun $^{-1}$ dengan membagi luas waduk dan dikalikan jumlah hari dalam satu tahun.

Pengambilan sampling outlet dilakukan di pintu air PLTA yang aliran mengarah ke Sungai Citarum. Hasil pengukuran TSS dan debit di outlet Waduk Jatiluhur disajikan pada Tabel 2.

Tabel 2. Hasil pengukuran outlet

\begin{tabular}{cccc}
\hline $\begin{array}{c}\text { Tanggal } \\
\text { Pengukuran }\end{array}$ & $\begin{array}{c}\text { C (Konsentrasi } \\
\text { Sedimen }) \\
\left(\mathrm{mg} \mathrm{l}^{-1}\right)\end{array}$ & $\begin{array}{c}\mathrm{Q}(\text { debit }) \\
\left(\mathrm{m}^{3} \mathrm{det}^{-1}\right)\end{array}$ & $\begin{array}{c}\text { QS(Debit } \\
\text { sedimen }) \\
\left(\mathrm{kg} \mathrm{det}^{-1}\right)\end{array}$ \\
\hline $16 / 01 / 18$ & 150 & 18.18 & 2.73 \\
$13 / 02 / 18$ & 160 & 29.94 & 4.79 \\
$18 / 03 / 18$ & 105 & 58.62 & 6.16 \\
$17 / 04 / 18$ & 290 & 22.92 & 6.65 \\
$15 / 05 / 18$ & 175 & 12.26 & 2.15 \\
$26 / 06 / 18$ & 135 & 55.82 & 7.54 \\
$17 / 07 / 18$ & 20 & 7.96 & 0.16 \\
$14 / 08 / 18$ & 145 & 6.59 & 0.96 \\
$13 / 09 / 18$ & 145 & 4.78 & 0.69 \\
$15 / 10 / 18$ & 163 & 4.44 & 0.72 \\
$13 / 11 / 18$ & 142 & 13.89 & 1.97 \\
$13 / 12 / 18$ & 70 & 14.68 & 1.03 \\
\hline
\end{tabular}

Berdasarkan data hasil pengukuran debit outlet Waduk Jatiluhur dan konsentrasi (Cs), maka dapat dihitung debit sedimen. Setelah mendapatkan nilai debit sedimen maka membuat persamaan lengkung debit sedimen, yaitu grafik hubungan antara Q dan Qs (Gambar 3).

Setelah mendapatkan debit harian selama satu tahun dan dikonversi ke dalam persamaan lengkung debit sedimentasi, maka menentukan debit sedimen (Qs) dalam ton hari ${ }^{-1}$. Debit sedimen (Qs) dalam ton hari-1 dihitung kembali menjadi satuan ton $\mathrm{ha}^{-1}$ tahun $^{-1}$ dengan membagi luas waduk dan dikalikan jumlah hari dalam satu tahun.

\section{Total Sedimen di Waduk Jatiluhur}

Perhitungan total sedimen pada Waduk Jatiluhur memerlukan data debit air dan data debit sedimen. Berdasarkan data tersebut maka dapat dihitung total sedimen tahun 2018 (Tabel 3).

Tabel 3. Total sedimen di Waduk Jatiluhur tahun 2018

\begin{tabular}{cccc}
\hline \multirow{2}{*}{ Bulan } & Inlet Waduk & Outlet Waduk & $\Delta \mathrm{S}$ \\
\cline { 2 - 4 } & (ton) & (ton) & (ton) \\
\hline Januari & $52,946.08$ & $7,304.00$ & $45,642.08$ \\
Februari & $71,515.42$ & $11,588.94$ & $59,926.49$ \\
Maret & $45,215.07$ & $16,485.82$ & $28,729.25$ \\
April & $72,695.75$ & $17,228.51$ & $55,467.24$ \\
Mei & $19,228.64$ & $5,746.51$ & $13,482.13$ \\
Juni & $31,404.67$ & $19,532.53$ & $11,872.14$ \\
Juli & $58,002.76$ & $4,26.40$ & $57,576.36$ \\
Agustus & $71,446.72$ & $2,559.35$ & $68,887.37$ \\
September & $31,150.94$ & $1,796.52$ & $29,354.42$ \\
Oktober & $25,144.77$ & $1,938.41$ & $23,206.35$ \\
November & $228,374.91$ & $5,282.82$ & $223,092.09$ \\
Desember & $152,242.68$ & $2,663.54$ & $149,579.14$ \\
\hline Total & $859,368.40$ & $92,553.33$ & $766,815.07$ \\
\hline
\end{tabular}

Berdasarkan data di atas menjelaskan bahwa sedimen yang mengendap di Waduk Jatiluhur pada tahun 2018 adalah 766,815.07 ton. Pada laporan Peruma Waduk Ir. H. Juanda Tahun 2000 dikatakan bahwa besarnya laju sedimen berasal dari aliran lokal ditambah dari hasil erosi yang terjadi di DAS Citarum dan Cirata sampai masuk ke waduk. Selain itu, kontribusi sedimen yang masuk ke waduk saat ini dan kemudian hari kemungkinan berasal dari lahan sabuk hijau, di sekeliling waduk yang dimanfaatkan oleh pemilik lahan perkebunan. Oleh karena itu, pemerintah harus mencegah adanya perluas an perkebunan penggunaan lahan lainnya yang dapat memperbesar kontribusi sedimen yang masuk ke waduk.

\section{SIMPULAN}

Total sedimen di inlet waduk adalah $859,368.40$ ton tahun $^{-1}$ dan outlet waduk adalah 92,553.33 ton tahun ${ }^{-1}$. Berdasarkan data tersebut maka total sedimen yang mengendap di Waduk Jatiluhur pada tahun 2018 adalah $766,815.07$ ton. Oleh karena itu, diperlukan penanganan dalam mengurangi sedimen agar waduk tidak mengalami pendangkalan.

\section{DAFTAR PUSTAKA}

Burton, G.A. 2018. Sediment Toxicity Assessment. CRC Press.

Hamzah, M.S. Maarif, Marimin dan E. Riani. 2016. Status mutu air waduk jatiluhur dan ancaman terhadap proses bisnis vital. Jurnal Sumber Daya Air, 12 (1): 47-60. 
Kementerian Kehutanan. 2014. Keputusan Menteri Kehutanan No.SK.61/Menhut-II/2014 tentang monitoring dan evaluasi Daerah Aliran Sungai. Sekretariat Jenderal. Jakarta.

Moerwanto, A.S. dan W.M. Putuhena. 2010. Pedoman Pengelolaan dan Pengukuran Sedimen. Pusat Litbang Sumber Daya Air. Bandung.
Peraturan Pemerintah Republik Indonesia Nomor 82. 2001. Tentang Pengelolaan Kualitas Air dan pengendalian Pencemaran Air.

Suripin. 2002. Pelestarian Sumber Daya Tanah dan Air. Andi. Yogyakarta.

Tjakrawarsa, G., R.N. Adi dan A.B. Supangat. 2014. Teknik Pengukuran Hasil Sedimen. Kementrian Lingkungan Hidup dan Kehutanan. Jakarta. 